\title{
Simulation Analysis for Concrete Hyperbolic Arch Dam of Gucheng Reservoir
}

\author{
Ji Dongyu \\ Hunan Urban Construction College \\ Xiangtan, China \\ hnjdy@126.com
}

\author{
Yang Zhichao \\ Yellow River Henan Bereau \\ Zhengzhou, China \\ yuluem@sina.com
}

\begin{abstract}
Concrete arch dam as an important hydraulic structures, in recent years has been widely used in water conservancy projects. Gucheng Reservoir is located in the ancient city of Yanqing County in Beijing, where is $10 \mathbf{~ k m}$ from the dam to the county, control drainage area above the dam $119 \mathrm{~km}^{2}$, which is an irrigation project, combined with the utilization of water projects for flood control, power generation and so on. In this paper, general finite element calculation software for concrete hyperbolic arch dam of Gucheng reservoir simulation analysis gives arch stress, deformation distribution in the course of construction and operation. The results for the design and construction of concrete hyperbolic arch dam structure provides a frame of reference, which has a certain theoretical significance. Arch upstream surface of the circumferential stress are substantially compressive stress, in addition, the first principal stress value smaller of the arch, which is able to meet strength requirements. The structure is safe and reliable.Meanwhile the deformation values is smaller of the arch, also to meet stiffness requirements.
\end{abstract}

Keywords-Gucheng reservoir; Concrete arch dam; Hyperbolic arch dam; Simulation analysis; Stress distribution.

\section{ENGINEERING SITUATION}

Gucheng Reservoir is located in the ancient city of Yanqing County in Beijing, where is $10 \mathrm{~km}$ from the dam to the county,control drainage area above the dam $119 \mathrm{~km}^{2}$, which is an irrigation project, combined with the utilization of water projects for flood control,power generation and so on[1].Reservoir design flood level is $55.47 \mathrm{~m}$ and corresponding to the downstream water level is $4.55 \mathrm{~m}$;Check flood level is $56.76 \mathrm{~m}$ and corresponding downstream water level is $4.55 \mathrm{~m}$.Project by dams, factories, irrigation and power generation water pipes,sediment scuppers,two dams and other buildings[2].The dam is a concrete hyperbolic arch dam,the maximum height of $65 \mathrm{~m}$, the dam bottom thickness 14 m,cross-sectional thickness arch higher than 0.22 , the maximum central angle $104^{\circ} 25^{\prime}$ and minimum central angle $66^{\circ}$, arch concrete strength class C20.

\section{ARCH CALCULATION MODEL}

\section{A Model Parameters}

The concrete arch dam of Gucheng reservoir uses the concrete strength class C20,elastic modulus $E_{1}=25.5 \quad \mathrm{GPa}, \quad$ poisson's ratio $\mu_{1}=0.167$ [3].Bulk density $\gamma_{1}=24 \mathrm{kN} / \mathrm{m}^{3}$. The rock for dam is dolomitic limestone. Rock elastic modulus $E_{2}=18 \mathrm{GPa}$ [4], Poisson's ratio $\mu_{2}=0.27$.

\section{B Model Element}

Concrete arch dam and bedrock structure model uses 8-node isoparametric block element[5].The element is applied to three-dimensional model entity structure, which has plasticity, creep, swelling, stress stiffening, large deformation and large strain characteristics.Element has eight nodes and each node has three translational degrees of freedom[6-7].

\section{Model Size}

The size of the entire calculation model is down the river to fetch $200 \mathrm{~m}$,perpendicular to the direction of the river to take $200 \mathrm{~m}$, vertical take $145 \mathrm{~m}$, simulation range model is $200 \mathrm{~m} \times 200 \mathrm{~m} \times 145 \mathrm{~m}$ [8-9].Arch and rock element division shown in Fig .1. 


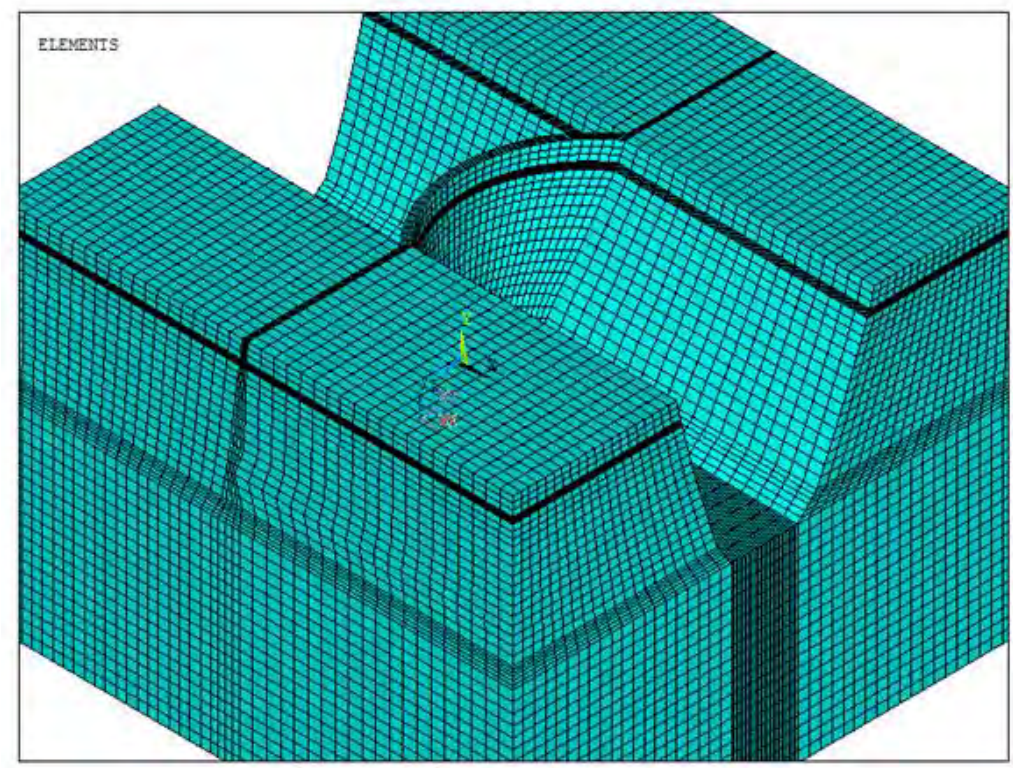

Figure 1. Arch and bedrock FEM division

\section{Calculation Condition}

Considering the arch structure during operation of the mechanical characteristics[10], the main consideration of the following four kinds of calculation condition is that case 1 (weight), case 2(design water level, tail water level and weight), case 3(check flood level, tail water level and weight), case4(design flood level, tail water level, weight and earthquake response).

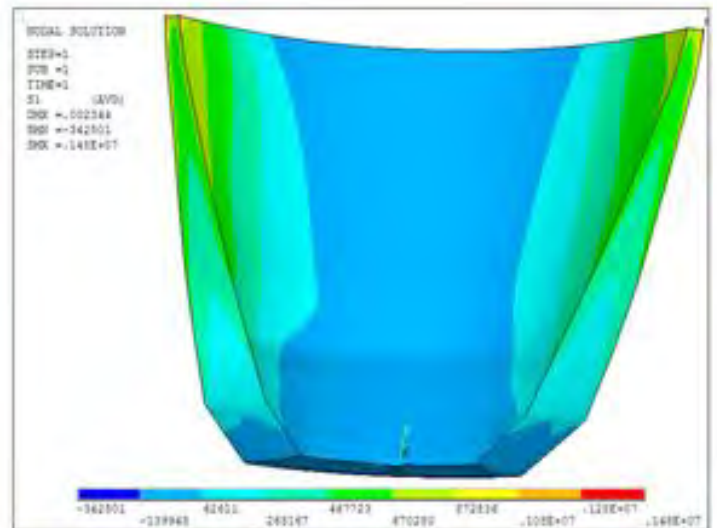

Figure 2. Cloud map of arch's first principal stress under case 1 $(\mathrm{Pa})$

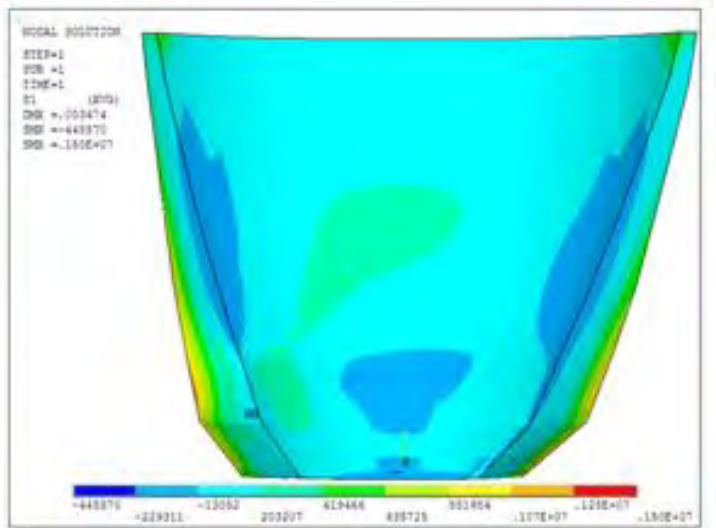

Figure 4. Cloud map of arch's first principal stress under case 2（Pa）

\section{ARCH STRUCTURE ANALYSIS}

\section{A Stress Analysis}

Each case of the arch about the first principal stress conditions of contour map and vertical stress of contour map,such as Fig .2 to Fig .9.

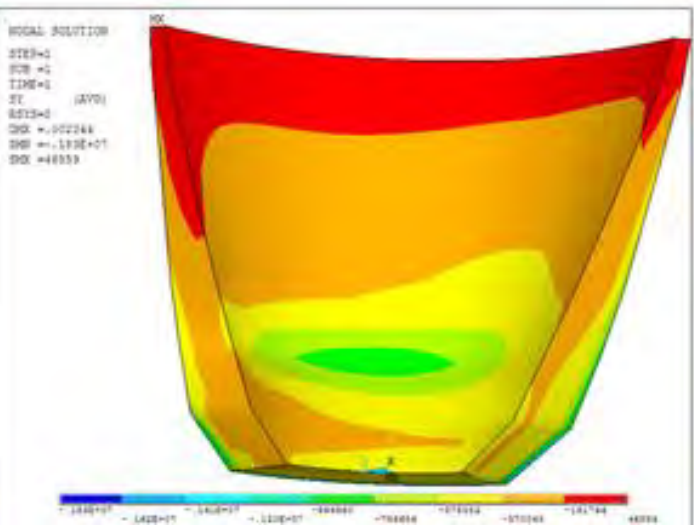

Figure 3. Cloud map of arch's vertical stress under case 1 ( $\mathrm{Pa})$

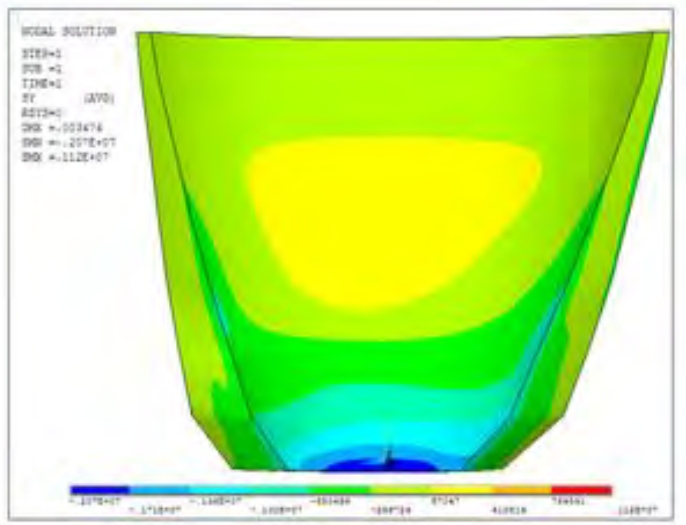

Figure 5. Cloud map of arch's vertical stress under case 2（Pa） 


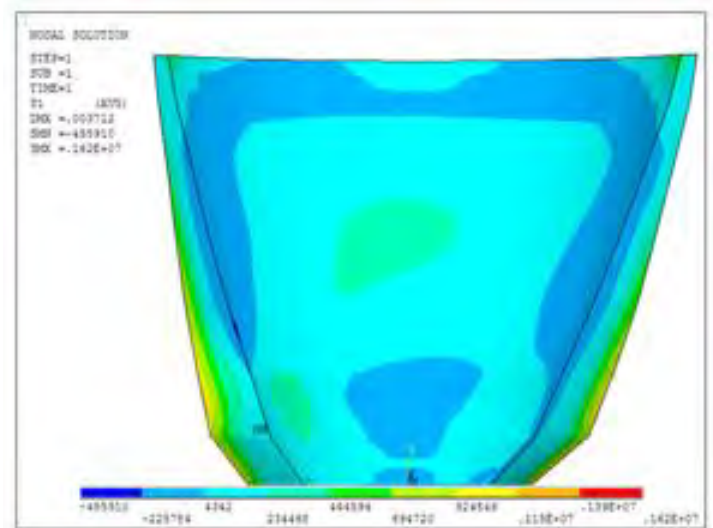

Figure 6. Cloud map of arch's first principal stress under case 3（Pa)

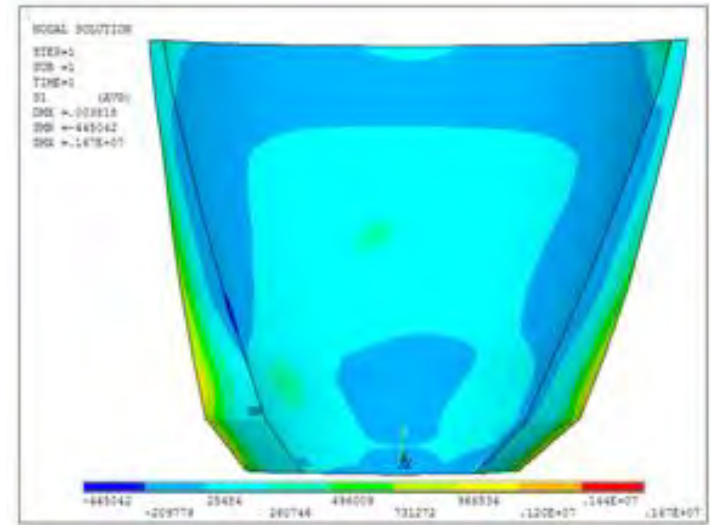

Figure 8. Cloud map of arch's first principal stress under case 4（Pa

As can be seen from Fig .2 to Fig .9, in the role of water pressure and weight, the first maximum principal stress and vertical stress present in arch dam and rock bottom junction. Under case 4, due to the earthquake, the largest arch dam is the first principal stress $1.67 \mathrm{MPa}$, the maximum vertical stress is $2.15 \mathrm{MPa}$, which appear in the upstream face of the bottom of the arch at the junction with the foundation, but it only occurs in within a few regions, belonging to the local stress concentration, there

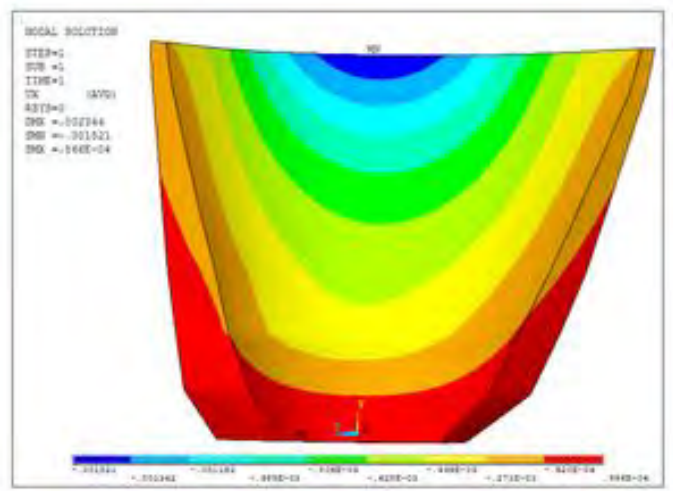

Figure 10. Cloud map of arch's radial displacement under case 1（m)

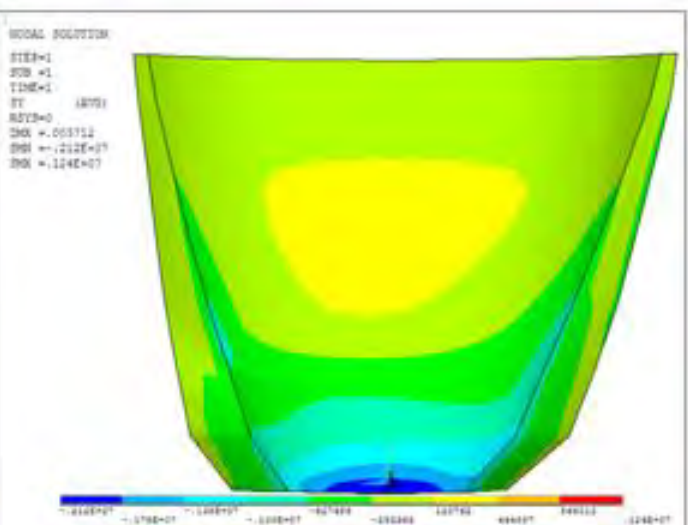

Figure 7. Cloud map of arch's vertical stress under case $3(\mathrm{~Pa})$

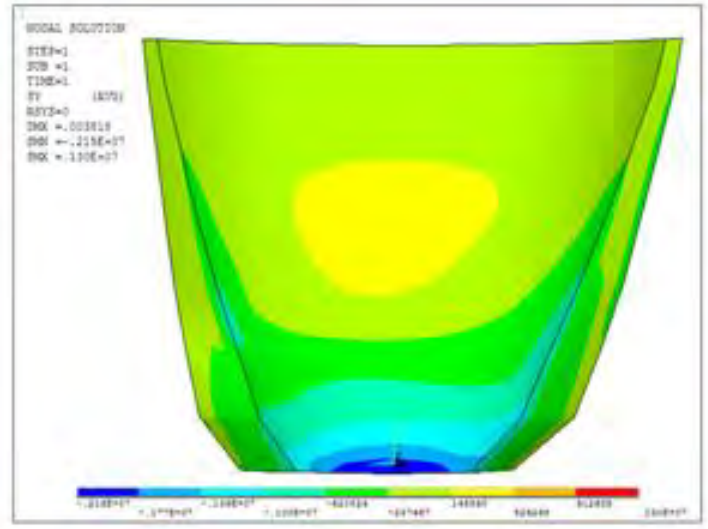

Figure 9. Cloud map of arch's vertical stress under case 4（Pa）

is no significant impact on the overall performance of the dam.

\section{B Deformation Analysis}

By deformation analysis of the concrete arch dam of Gucheng reservoir,we calculated radial displacement of each condition maps arch ,and the dam radial displacement cloud shows in Fig .10 to Fig .13.

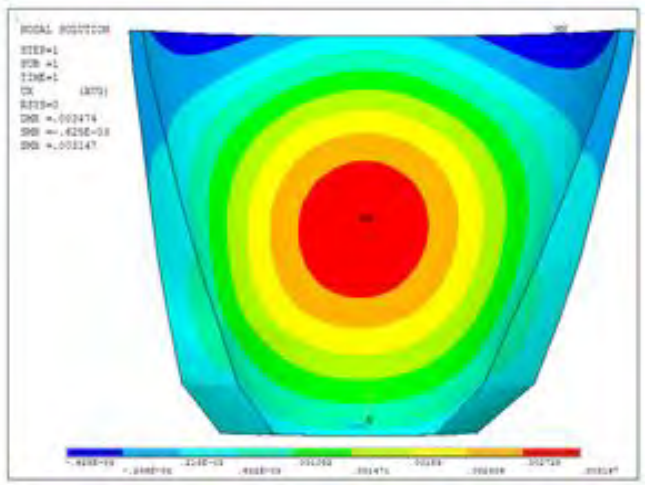

Figure 11. Cloud map of arch's radial displacement under case $2(\mathrm{~m})$ 


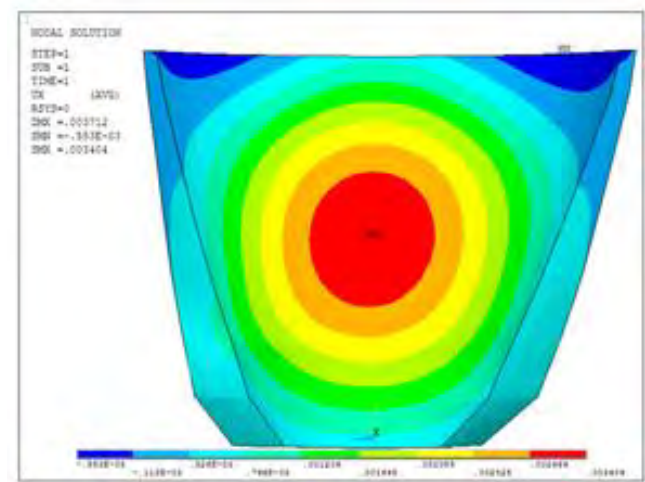

Figure 12. Cloud map of arch's radial displacement under case $3(\mathrm{~m})$

From the Fig .10 to Fig .13 can be seen that under its own weight,the radial displacement of the arch of the basic layered distribution.The maximum radial displacement occurs at the top of the dam. Under the combined effect of water pressure and weight,the maximum radial displacement occurs in the middle of the arch crown arch,but the smaller radial displacement values appear in the junction that is bedrock and abutment.

\section{CONCLUDING REMARKS}

In summary, the use of the concrete arch dam in Gucheng reservoir scheme is reasonable. Arch upstream surface of the circumferential stress are substantially compressive stress, in addition, the first principal stress value smaller of the arch, which is able to meet strength requirements. The structure is safe and reliable. Meanwhile the deformation values are smaller of the arch, also to meet stiffness requirements.

\section{REFERENCE}

[1] Khaled H. Bayagoob,Jamaloddin Noorzaei,Aeid A. Abdulrazeg et al. Coupled thermal and structural analysis of roller compacted concrete arch dam by three-dimensional finite element method [J]. Structural engineering and mechanics,2010,36(4):401-419.

[2] Wen-ping Fei, Lin Zhang, Ru Zhang et al. Experimental study on a geo-mechanical model of a high arch dam [J]. International

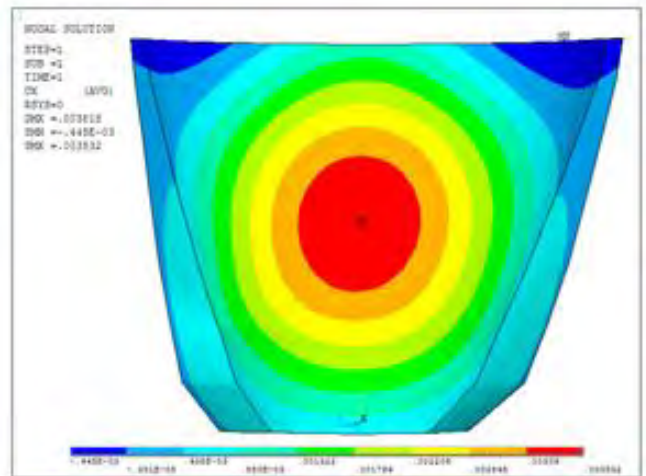

Figure 13. Cloud map of arch's radial displacement under case $4(\mathrm{~m})$

Journal of Rock Mechanics and Mining Sciences, 2010, 47(2):299-306

[3] SL191-2008. Design Code for Hydraulic Concrete Structure[S] China Water Conservancy and Hydropower Press, 2008.

[4] Mingrong Shen, Jianfeng Chen. Rock mechanics [M]. Tongi University Press, 2006.

[5] Xucheng Wang. Finite Element Method [M]. Tsinghua University Press, 2003.

[6] Bang-Fuh Chen,Yin-Sen Yuan. Hydrodynamic Pressures on Arch Dam during Earthquakes [J]. Journal of hydraulic engineering,2011,137(1):34-44.

[7] Baris Sevim,Alemdar Bayraktar,Ahmet Can Altunisik et al. Moda Parameter Identification of a Prototype Arch Dam Using Enhanced Frequency Domain Decomposition and Stochastic Subspace Identification Techniques[J] . Journal of Testing and Evaluation,2010,38(5):588-597.

[8] Seyed Mohammad Seyedpoor,Javad Salajegheh,Eysa Salajegheh et al. Shape optimal design of materially nonlinear arch dams including dam-water-foundation rock interaction using an improved PSO algorithm [J]. Optimization and engineering,2012,13(1):79-100

[9] Bans Sevim,Alemdar Bayraktar,Ahmet Can Altunisik et al. Investigation of water length effects on the modal behavior of a prototype arch dam using operational and analytical modal analyses $[\mathrm{J}]$. Structural engineering and mechanics,2011,37(6):593-615.

[10] Bofang Zhu, Jizhang Gao, Zuyu Chen, Yisheng Li. Arch Dam Design and Research $[\mathrm{M}]$. China Water Conservancy and Hydropower Press, 2002. 